\title{
Cancer-Related Stress and Complementary and Alternative Medicine: A Review
}

\author{
Kavita D. Chandwani, Julie L. Ryan, Luke J. Peppone, Michelle M. Janelsins, Lisa K. Sprod, \\ Katie Devine, Lara Trevino, Jennifer Gewandter, Gary R. Morrow, and Karen M. Mustian
}

\author{
James P. Wilmot Cancer Center, Department of Radiation Oncology, School of Medicine and Dentistry, University of Rochester Medical \\ Center, Saunders Research Building, 265 Crittenden Boulevard, Office 2.224, Box CU 420658, Rochester, NY 14642, USA \\ Correspondence should be addressed to Kavita D. Chandwani, kavita_chandwani@urmc.rochester.edu
}

Received 2 January 2012; Accepted 1 June 2012

Academic Editor: Alyson Huntley

Copyright ( $\odot 2012$ Kavita D. Chandwani et al. This is an open access article distributed under the Creative Commons Attribution License, which permits unrestricted use, distribution, and reproduction in any medium, provided the original work is properly cited.

A cancer diagnosis elicits strong psychophysiological reactions that characterize stress. Stress is experienced by all patients but is usually not discussed during patient-healthcare professional interaction; thus underdiagnosed, very few are referred to support services. The prevalence of CAM use in patients with history of cancer is growing. The purpose of the paper is to review the aspects of cancer-related stress and interventions of commonly used complementary and alternative techniques/products for amelioration of cancer-related stress. Feasibility of intervention of several CAM techniques and products commonly used by cancer patients and survivors has been established in some cancer populations. Efficacy of some CAM techniques and products in reducing stress has been documented as well as stress-related symptoms in patients with cancer such as mindfulness-based stress reduction, yoga, Tai Chi Chuan, acupuncture, energy-based techniques, and physical activity. Much of the research limitations include small study samples and variety of intervention length and content. Efficacy and safety of many CAM techniques and some herbs and vitamin $\mathrm{B}$ and $\mathrm{D}$ supplements need to be confirmed in further studies using scientific methodology. Several complementary and alternative medicine therapies could be integrated into standard cancer care to ameliorate cancer-related stress.

\section{Introduction}

Cancer-related distress is defined as an "unpleasant emotional experience of a psychological, social, and/or spiritual nature that may interfere with the ability to cope effectively with cancer, its physical symptoms, and its treatment" [1]. Several factors can cause stress during the cancer experience; a cancer diagnosis itself is a strong stressor associated with "disbelief, anxiety, depression," and disturbances of sleep, appetite, and routine daily activities [2]. In addition to uncertainty about the disease and its treatment, there is also fear of death, disease progression, reduction in quality of life (QOL) and relationships, a loss of sense of control [3-10], and impacts on decision-making ability and treatment compliance [1]. Cancer patients experience a broad spectrum of individual and cooccurring symptoms such as pain, anxiety, depression, fatigue, nausea, diarrhea, wasting, and cognitive impairments, which both promote and indicate distress [11]. Regardless of treatment regimen, distressing symptoms such as fatigue, insomnia, pain, depression, hot flashes, sexual dysfunction, and cognitive deficits frequently occur and often persist following treatment $[12,13]$. Overall, a cancer diagnosis creates a vicious and compounding cycle of stress.

Although all patients with a history of cancer experience variable level of stress across the continuum of disease [1], often information sharing on this topic does not happen during interaction of patients with their healthcare professionals [1]. The reported prevalence of cancer-related distress is $24-59 \%$ depending on the type of cancer [10], stage of disease, patient population studied, and study setting [14, 15]. A recent study of newly diagnosed cases reported distress in about $67 \%$ of lung cancer patients and $50 \%$ of breast cancer patients [16]. Another study found self-reported distress in $25 \%$ of cancer outpatients, $59 \%$ of patients with advanced 
cancer undergoing palliative care, and $16 \%$ of cancer patients in the general community [14]. Psychosocial interventions including experiential-existential group psychotherapy and cognitive-behavioral stress management [17-22] have shown positive results in coping with daily stressors. Additionally, pharmacologic treatments for some of the cancer-related psychiatric symptoms are available. Some resources are available in the form of information on its identification and possible counseling services recommended by various national societies and institutions [1]. However, only a small percentage of patients with distress are detected and referred for treatment [1]. The use of complementary and alternative medicine (CAM) has increased among cancer patients at the time of diagnosis, during treatment, and even after treatment is complete [23]. The primary reasons for CAM use by cancer patients are pain relief, immunesystem boost, symptom management [24], and better quality of life [25]. However, there are concerns about the use of CAM techniques related to cancer experience since the efficacy of several of these techniques/products has not been documented or due to possibility of interaction with treatment. This paper reviews aspects of cancer-related stress and CAM interventions for the amelioration of stress during and after the cancer experience. Researchers over time have used the words "stress" and "distress" interchangeably, and in this paper, the term "stress" will be used unless the referenced study used the word "distress".

\section{Neuroendocrine and Immunological Aspects of Stress and Cancer}

Stress is characterized by psychophysiological processes in response to an event or circumstance that is perceived as threatening, harmful, or challenging [26]. The hypothalamus-pituitary-adrenal (HPA) axis and the sympathetic nervous system (SNS) are involved in the physical stress response. The HPA axis functions through a negative feedback system: increased cortisol and other glucocorticoid (GC) levels inhibit release of corticotrophin-releasing hormone $(\mathrm{CRH})$ and adrenocorticotropic hormone (ACTH) from the neurons of the hypothalamus and pituitary gland, respectively, leading to a reduction in GC levels (Figure 1(a)). A chronic or repeated exposure to a stressor decreases $\mathrm{CRH}$, ACTH, and GC levels $[27,28]$ indicating a reduction in negative feedback in the HPA axis. In cancer patients, such dysregulation of the HPA axis and the SNS may be related to the development, maintenance, and recurrence of cancer. For instance, norepinephrine has been linked to the etiology of cancer [29], and epinephrine has been shown to protect against cellular apoptosis in cancer cells [30]. In women with metastatic breast cancer, HPA axis dysregulation was characterized by increased resting cortisol levels (Figure 1(b)) and decreased inhibition of the pituitary gland and the hypothalamus [31]. Although a linear relationship between resting cortisol levels and stage of cancer was observed, ACTH levels were normal in both early and late stages [31]. Other studies have shown that some cancer patients have a flattened diurnal cortisol rhythm compared to healthy controls $[32,33]$, which is associated with shorter survival times [33].

Stressful events like cancer have been shown to lead to increased risk of disease progression and decreased survival [34-37], and they can contribute to dysregulation of the immune system, chronic inflammation, and numerous adverse effects [38]. Psychological stress and altered HPA axis function can influence the activity of a variety of immune cells, including natural killer (NK) cells, T cells, and macrophages [39]. Disrupting the balance of immune cells leads to a chronic proinflammatory cytokine-mediated cascade of events resulting in enhanced psychological stress, depression, anxiety, fatigue, sleep disturbance, cognitive impairments, and ultimately reduced quality of life [40-44]. Stress hormones can impair the immune response and may affect tumor progression and cancer prognosis. Chronically elevated stress hormones shift the balance between the Th1 (cellular) and Th2 (humoral) immune responses toward the Th2 response. Expression of Th1 cytokines IFN- $\gamma$ and IL12 decreases during stress, while Th2 cytokines IL-4, IL5, IL-6, IL-10, and IL-13 increase (reviewed in $[45,46]$ ). These changes are associated with decreased cytotoxic Tlymphocyte and natural killer (NK) cell activity [47, 48]. Evidence from animal models suggests that these types of immune deficiencies can lead to tumor progression. For example, mice subjected to social isolation stress had decreased splenic NK cell activity [49]. In the same mice, metastasis required less time after tumor cell injection in stressed animals than in controls. Stressed animals also did not respond as well to chemotherapy [50].

Stress hormones can also alter cell-signaling pathways, which have been implicated in cancer progression. Many studies suggest that stress hormones can decrease apoptosis in certain cancer cells through decreased activity of proapoptotic caspases-3, 8, and 9 [51] and protein BAD [52]. Increases in vascular endothelial growth factor (VEGF), which is important for tumor vascularization and survival [53], have been shown in cancer cell culture models as a result of norepinephrine-dependent $\beta$-adrenoreceptor activation of the CAMP/PKA signaling pathway [54-56], and this could be critical in tumor progression. In an animal model of ovarian cancer, psychological stress simultaneously increased VEGF expression and tumor burden [57].

Metastasis relies on tumor cell invasion, which requires proteins that can break down the extracellular matrices of the invaded tissues; preliminary evidence of the same is provided by norepinephrine-stimulated ovarian cell invasion and increased matrix-metalloproteinase- (MMP-)2 and 9 expression through activation of the $\beta$-adrenergic receptor [58] and an increase in MMP-2 and 9 associated with psychological stress in the ovarian cancer mouse model [57]. Thus, it is conceivable that stress management might reduce disease progression and improve quality of life in patients with cancer. We note that while this is a plausible hypothesis, the evidence supporting it in cancer patients is lacking. Several modalities for stress reduction have shown promise; use of other options can be considered based on evidence provided by recent research on complementary and alternative medicine (CAM) techniques/products. 


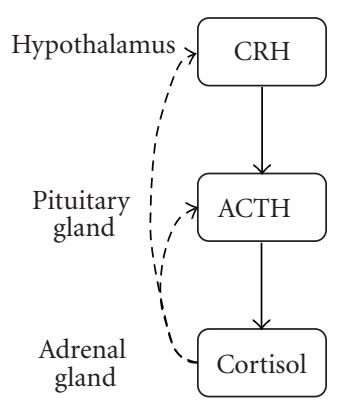

(a) Normal HPA-axis regulation

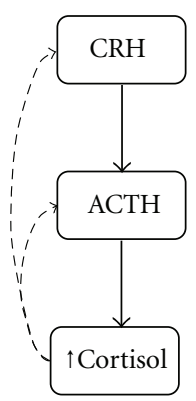

(b) Proposed

HPA-axis

dysregulation

for high cortisol

levels

Figure 1: Overview of the hypothalamus-pituitary-adrenal axis in relation to the stress response in healthy individuals (a) and those with cancer (b). CRH: corticotrophin-releasing hormone; ACTH: adrenocorticotropic hormone. Thin dashed lines represent reduced feedback inhibition.

\section{Complementary and Alternative Medicine Utilization in Cancer}

CAM has been defined by the National Center for Complementary and Alternative Medicine (NCCAM) as "a group of diverse medical and health care systems, practices, and products that are not generally considered part of conventional medicine" [59]. Such techniques include mindbody medicine, natural products, nutritional supplementation, manipulative body-based practices, energy-based techniques, and traditional medical systems (e.g. Chinese, Ayurved, and American-Indian). These modalities have recently been classified as integrative medicine as they are not an alternative to conventional medicine use; however, for the purpose of this paper the term CAM will be employed. CAM use has been increasing among cancer patients [23] and currently ranges from $22 \%$ to $73 \%$ [60]. Based on 2002 National Health Interview data, $26 \%$ of female survivors and $13.7 \%$ of male cancer survivors reported using CAM [61]. A more recent study revealed that $62 \%$ of female breast cancer survivors used CAM [62]. CAM use in cancer patients is associated with high levels of distress and failure of conventional medicine to meet psychosocial needs [63]. Although emotional distress along with other psychological indices significantly predicted CAM use in male and female survivors of colon cancer [64], a study of predictors of CAM use in early-stage breast cancer within a year of diagnosis suggested that such use may be motivated by the expected benefits and may not necessarily indicate distress or dissatisfaction [65].

\section{Mind-Body Medicine}

Mind-body medicine (MBM) includes a variety of practices that enable the mind to influence body functions. Some of the early works in the area of MBM include research on transcendental meditation (TM) [66-69] and application of meditation techniques for stress reduction by Kabat-Zinn [70]; the latter was called mindfulness-based stress reduction
(MBSR). MBM is increasingly used by breast cancer patients [71]. A recent study reported that $64.2 \%$ of breast cancer patients practiced mind-body techniques following their diagnosis, and this usage was associated with Hispanic race, higher education, low income, and other CAM use [72]. Research on MBM in cancer has grown in the past decade, although the majority of studies have been conducted in the breast cancer population. Moreover, studies have used a variety of designs, intervention programs, and measures to evaluate effects, and most of the research has involved small sample sizes. Larger studies are needed to confirm the effects of many mind-body techniques on common symptoms of cancer and its treatment.

Several studies in cancer patients have examined the effect of meditation and yoga on quality of life, fatigue, and sleep [73-80]. Mindfulness-based stress reduction (MBSR), a program that includes meditation, yoga postures, and relaxation [81], helps patients understand their personal responses to stress and teaches them how to modify their responses. A program of MBSR reported lower levels of total mood disturbance and distress [82] as well as significant improvements in mood, sleep quality, and fatigue in a mixed cancer population [83]. Other studies using MBSR interventions in cancer patients have shown decreases in stress symptoms and cortisol levels and improvements in patient-reported quality of life [74]. A recent randomized controlled trial of a 6-week MBSR program for breast cancer survivors reported reduced anxiety, depression, and fear of recurrence and better perception of physical functioning in the intervention group [78].

Sixteen studies have shown that participation in programs consisting of traditional holistic yoga results in statistically significant improvements in stress, anxiety, irritability, emotional well-being, sadness, energy, invigoration, cognitive function, relaxation, pain, sleep, mood, depression, fatigue, symptom severity, hot flashes, appetite, bowel function, nausea, vomiting, QOL, and tolerance of cancer treatment $[73,75,76,84-96]$. The yoga interventions typically lasted from 6 to 24 weeks and most often involved 
weekly sessions of 75-120 minutes. The types of yoga used in the interventions also varied; the majority of the interventions used systems of yoga that involved meditation, breathing, gentle yoga, and restorative yoga. These studies indicate that clinicians and patients are very receptive to stress reduction programs, including yoga, as a treatment modality in traditional cancer centers and that it is feasible to recruit patients and conduct these types of interventions in a wide variety of communities. A large community-based trial of a yoga program in cancer survivors was found to improve their sleep, fatigue, quality of life [97], circadian rhythm, anxiety, and mood [98]. Some studies of yoga have examined its effects on measures of stress and its physiologic parameters. Yogic relaxation training has been found to reduce perceived stress after surgery in breast cancer [99]; another study of yoga during radiation treatment in breast cancer patients observed a $27 \%$ reduction in perceived stress score [84]. A recent study of Iyengar yoga in breast cancer survivors observed reduced morning and evening cortisol levels along with improved fatigue, emotional well-being [73], and vitality and reduced pain [96] following eight- and twelve-week interventions.

Tai Chi Chuan (TCC) is a form of martial arts used for centuries in China as a health exercise involving a series of individual movements continuously linked together and performed in conjunction with deep breathing and mental concentration. At least 20 prospective, randomized, controlled clinical trials in a number of populations including the elderly, cardiovascular patients, and patients with chronic diseases have been conducted using TCC [100]. TCC as an intervention may provide benefits to cancer survivors related to physical deconditioning, cardiovascular disease risk, and psychological stress. In a randomized, controlled clinical trial conducted by Mustian et al., women who completed treatment for breast cancer and received TCC demonstrated significant improvements in functional capacity, aerobic capacity, muscular strength and flexibility, self-esteem, bone health, immune function, and QOL [101-106]. Thus, physical activity seems to be an intervention capable of reducing anxiety and distress associated with the cancer experience. Conversely, higher levels of anxiety may reduce the likelihood of participation in physical activity following cancer treatment.

Acupuncture, a mind-body technique that is also classified as manipulative body-based technique and energy-based technique, has been shown to ameliorate distress in healthy adults [107]. It has also been found to reduce fatigue and distress in patients with advanced breast and ovarian cancer [108]. A recent systematic review of 15 studies of CAM interventions (acupuncture, massage, yoga and relaxation, hypnosis, vitamins, and medical qigong) in cancer-related fatigue reported most benefits from acupuncture [109]. Acupuncture has also been found beneficial in cancer-related vasomotor symptoms [110] and anxiety associated with hot flashes [111] and other symptoms associated with cancer such as pain, nausea and vomiting, fatigue that could be related to stress [112]. Another MBM technique, hypnosis, combined with cognitive behavioral therapy prevented the increase of fatigue in breast cancer patients compared to standard medical care during radiation therapy [113] and reduced fatigue in women who underwent lumpectomy for breast cancer [114].

\section{Herbal and Natural Products}

The use of herbal and natural supplements has dramatically increased over the last ten years. Herbal (or natural) supplements are commonly used to combat stress-related symptoms such as anxiety, depression, insomnia, and fatigue [115-117]. Herbal supplements are one of the three most common forms of CAM used by cancer patients [116-119]. In a recent study conducted by MD Anderson Cancer Center, $52 \%$ of 309 cancer patients reported using one or more forms of CAM modalities, and 26\% reported herbal supplement usage [118]. Unfortunately, little evidence supports the effectiveness of herbal interventions for long-term reduction in stress $[115,116]$.

Sedative herbal and natural supplements have been used since the middle ages to reduce stress and improve quality of life. Herbal supplements are usually ingested as extracts (i.e., tea) or capsules or inhaled as essential oils (i.e., aromatherapy). Commonly used herbal supplements for stress include lemon balm, kava, valerian root, lavender, St. John's wort, and passionflower [115-117]. Lemon balm has proven effective and safe for relieving stress with long-term use [116, 120-123]. Substantial evidence indicates that kava reduces anxiety and stress; however, it has been implicated in liver failure and is therefore not clinically recommended but may be safe for short-term use in patients with mild to moderate anxiety $[115,116,119,122,124,125]$. Although valerian is considered safe at low doses for less than one month, no clinical evidence supports its use for anxiety or distress [116, 121-123, 125]; however, combined with lemon balm and kava it has been associated with reduction in stressrelated insomnia $[120,121,125]$. Lavender aromatherapy is recommended to relieve anxiety and depression and promote calmness and positivity, but definitive evidence for efficacy is lacking [117, 123, 124]. A randomized controlled trial which combined lavender essential oils with massage in patients with cancer reported reductions in distress, but the study was not able to conclude whether lavender aromatherapy supplemented the effects of massage [124]. Likewise, passionflower demonstrated a reduction in anxiety compared to oxazepam $[116,126]$. St. John's wort is used mostly for depression and is less popular for treating anxiety and distress [116]. Some evidence suggests that Siberian ginseng and European mistletoe may reduce side effects of cancer treatment and improve quality of life [127-129]. Possible mechanisms of some herbals in stress are depicted in Figure 2. Thus patients with high levels of stress could benefit from herbal supplements [116-118, 124] but patients should discuss any proposed supplement use with their physician to ensure safety.

Researchers have studied the effects of numerous vitamins, minerals, and dietary supplements on psychological stress. The most promising include the $\mathrm{B}$ vitamins (folic acid, B6 and B12) and vitamin D. However, there is a 
dearth of investigation of the effects of these compounds on psychological distress in cancer patients, perhaps due to the reluctance of oncologists to prescribe vitamin and mineral supplementation during treatment, believing that the antioxidant effects of these supplements might decrease treatment efficacy. Nevertheless, the few studies available show that vitamin and mineral supplementation administered during treatment do not reduce treatment efficacy $[130,131]$. Following the completion of treatment, cancer survivors use vitamin and mineral supplementation at a higher rate than the general population, with $64-81 \%$ of cancer survivors using supplements compared to approximately $50 \%$ of the general population [132].

A large amount of the literature reports the effects of $B$ vitamins (folic acid (B9), pyridoxine (B6), and cobalamins (B12)) on psychological stress, particularly depression. There is a biological rationale for the association of $\mathrm{B}$ vitamins with psychological stress. B vitamin deficiency can lead to an increase in homocysteine levels [133], which is associated with increased depression rates [134]. Cross-sectional studies commonly find that patients with psychological stress disorders have deficient folic acid levels [135-137]. Similar findings were reported for vitamin B12, with low levels seen in patients with psychological distress [138140]. Evidence from cross-sectional studies also indicates that psychologically stressed patients have low levels of vitamin B6 [141, 142], but the evidence is not as strong as for folic acid or vitamin B12. Other studies show that individuals deficient in B vitamins have a poorer response to antidepression therapy and higher rates of relapse of depression. Randomized trials have shown that adding folic acid and vitamin B12 supplementation to existing treatments increases the efficacy of antidepressant treatment [143-145].

Recent research has shown that vitamin $\mathrm{D}$ may be involved in psychological well-being. Vitamin D plays a crucial role in brain development and function [146, 147]. A recent study in fibromyalgia patients found a significantly higher rate of vitamin $\mathrm{D}$ deficiency in patients with anxiety [148]. Other studies have associated vitamin D deficiency with cognitive impairment $[149,150]$, mood disorders [150], and depression [148, 151]. Vitamin D deficiency has also been associated with seasonal affective disorder (SAD), a condition with depression-like symptoms that occur in winter, when vitamin $\mathrm{D}$ levels are typically at their lowest [152]. Randomized trials also show that vitamin D supplementation may ameliorate symptoms of depression [151] and SAD $[153,154]$. Thus, research indicates that individuals with low levels of folic acid, vitamin B12, and vitamin D have higher rates of psychological stress, and limited evidence from randomized trials show that supplementation with these vitamins may improve anxiety, mood disorders, and depression.

\section{Manipulative and Other CAM Therapies}

Research on massage therapy, a manipulative body-based technique, for stress reduction in cancer populations has not provided consistent results [164-167]. Polarity Therapy,
Reiki, therapeutic touch, healing touch, and Qigong involve manipulation of the body energy fields. Polarity therapy (PT) has been shown to reduce cancer-related fatigue during radiation treatment [168] when compared with modified massage therapy and standard care [169]; the potential for its use in management of cancer-related stress can be explored since PT has been shown to decrease stress in caregivers of dementia patients [170]. The fact that Reiki ameliorates pain in advanced cancer patients [171] and reduces cancer-related fatigue [172] may indicate that it can also lower cancerrelated stress, although there is no supporting evidence. The trials of music in reducing stress in cancer have not yielded consistent results; one study in women with metastatic breast cancer showed no significant differences in the music therapy led by a therapist and the usual care groups [173]. However, one study of music imagery intervention has suggested reduction of anxiety in adults undergoing chemotherapy, particularly those with lower initial stress levels [174].

\section{Exercise}

Exercise training improves resilience to stress $[175,176]$. A 6-week exercise intervention in patients receiving chemotherapy was found to have beneficial effects on psychological distress [177]. Similarly, in postoperative breast cancer patients receiving chemotherapy, a 12-week home-based exercise intervention was found to improve mood disturbance compared to a nonexercise control group [178]. Researchers have found that cancer patients who exercised before undergoing treatment for cancer experienced lower levels of anxiety and depression [179]. Early-stage breast cancer patients undergoing a 6-week walking exercise intervention during radiation treatment also noted improvements in anxiety [180]. In colorectal cancer survivors, a relationship was established between psychological distress, anxiety, and participation in physical activity. Cancer survivors with higher levels of anxiety are less likely to participate in physical activity [181].

\section{CAM in Children, Adolescents, and the Elderly with Cancer}

A recent systematic review estimated that the prevalence of CAM use by children with cancer ranges from $6 \%$ to $91 \%$, with significant variation between studies [182]. Children's and adolescents' use of CAM has been linked to parents' use of CAM [183, 184]. Parents with higher educational backgrounds are more likely to consider [185] and to use [182] CAM approaches for their children, although no consistent correlations between CAM use and parental income, child age, or ethnicity have been reported [182]. CAM use and consideration were shown to be positively related to a lower survival perspective [186] and fewer days since relapse [185], respectively, suggesting that CAM therapies may be a coping strategy for families in an attempt to try every possible approach for curing or alleviating pain and distress in their children. A review by Sencer and Kelly [187] suggests that families' use of CAM may increase their 


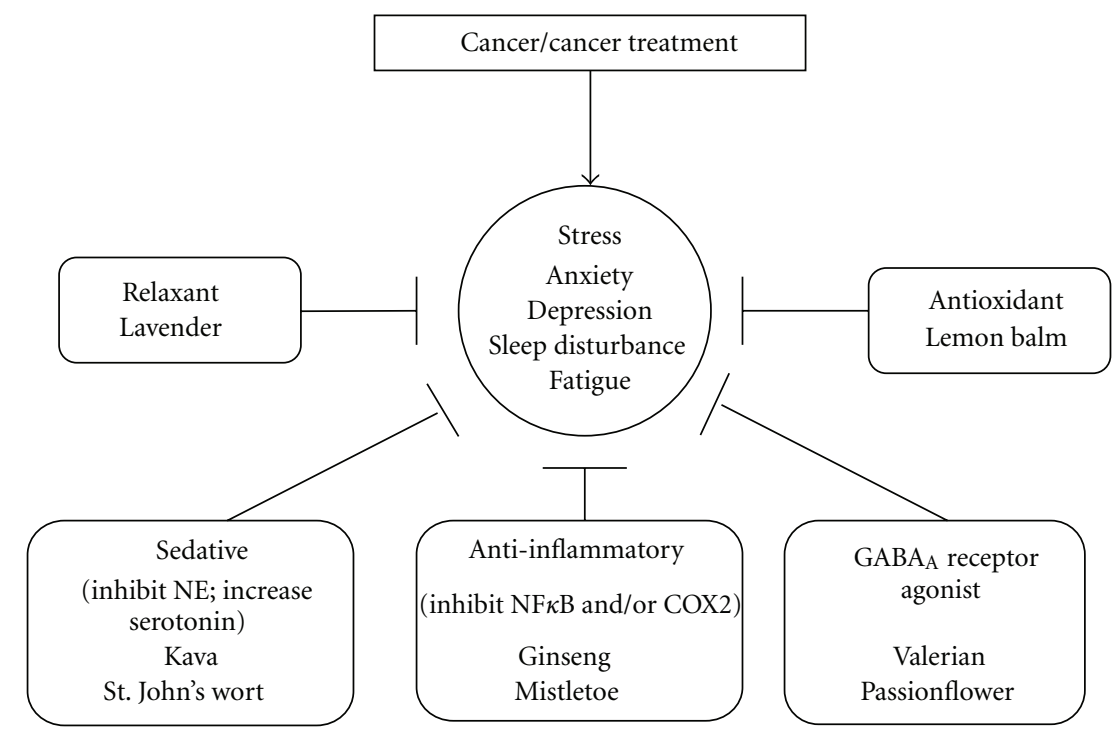

Figure 2: Mechanisms of herbal supplements for stress. Cancer and cancer treatment affect a patient's quality of life resulting in various symptoms of stress, such as anxiety, depression, sleep disturbance, and fatigue [155]. The human body's response to such stressors involves many different mechanistic pathways. This diagram outlines the mechanisms by which herbal supplements reduce stress-related symptoms in cancer patients. The majority of herbal supplements have anti-inflammatory properties, but their primary target of action is different. Lavender acts as vascular smooth muscle relaxant through nitric oxide/cGMP phosphorylation and myosin light chain dephosphorylation [156]. Lemon balm is an immune stimulating agent with potent free radical scavenging properties [157-159]. Kava and St. Johns's wort function reduce norepinephrine (NE) and increase serotonin levels, similar to antianxiety drugs such as benzodiazepines [116, 122, 160]. Valerian and passionflower are $\mathrm{GABA}_{\mathrm{A}}$ receptor agonists that produce a sedative effect $[161,162]$. Ginseng and mistletoe are potent antiinflammatory agents that inhibit NFkB and/or COX2 [127, 163].

sense of control and active participation in treatment, and therefore open discussion of CAM should be useful for physicians in building relationships with families and in understanding all potential influences on the child's care.

The quality of research related to CAM use in pediatric oncology has varied greatly from study to study. Within the past 10 years, there has been considerable movement towards more rigorous research testing, including randomized clinical trials conducted through the Children's Oncology Group or other multisite studies [188-191]. There is a great need for rigorous safety and efficacy trials, particularly for biologically based therapies [188, 192]. Research has reported physical and psychological benefits from a massage intervention for children with various cancers and blood disorders [193]; however, another randomized trial of a combined massage and humor intervention found no significant differences across groups in children undergoing stem cell transplants [190]. A trial of music video compared to audiotape and usual care in adolescents and young adults undergoing stemcell transplantation suggested less distress in music group at 100-day follow-up [194]. Thus, several promising CAM therapies are available to help children with cancer to manage emotional and physical distress related to cancer and its treatment; however, much work is needed to document their efficacy and safety.

Aging alone is associated with declines in physical function, including reduction in functional capacity [195, 196], reduced muscular strength [197], arthralgia [198], and reductions in bone mineral density [199]. Depression [200], anxiety [201], and cognitive difficulties [202] also affect older adults. Cancer treatments can further exacerbate these agerelated declines and stressors. Cancer survivors aged 65 and older report more limitations in activities of daily living [203], a lower quality of life [204], lower self-rated health [204], a greater incidence of frailty [203], and higher rates of dementia, depression, falls, incontinence, and osteoporosis [203]. Other stressors in this population include relocation, financial changes with retirement, caring for grandchildren and/or a spouse, the death of friends and family members, chronic illnesses, and the fear of losing independence [205-208]. Stress is associated with depression in the elderly [209]. Emotional stress is also a potential trigger impairing the mechanisms responsible for balance, increasing the risk of falls that can lead to hip and femur fractures [210]. These additional declines in physiological and psychological function likely exacerbate the stress experienced by older cancer survivors.

Physical activity and social interactions reduce functional decline in the elderly [211]. Physical activity is also associated with a reduction in stress and anxiety. The American College of Sports Medicine (ACSM) recommends that older adults, even those with chronic medical conditions, participate in regular aerobic exercise training (150-300 minutes per week) and resistance exercise training (at least 2 days a week) [212]. The exercise prescription for those older adults who are functionally limited should be tailored and progressed gradually [213]. The literature supports the use of physical activity in cancer survivors younger than 65 , but little has 
been done to determine the benefits of physical activity or other forms of complementary and alternative medicine for cancer survivors who are 65 years of age and older. Researchers have investigated the benefits of Tai Chi Chuan in older adults without a history of cancer, finding that Tai Chi can reduce depression [214], improve self-efficacy [215], improve muscular strength and endurance [216], and improve balance and reduce falls [217]. Yoga can improve gait [218], quality of life [219], and depression [220] in the elderly. Research is limited concerning the implementation of CAM in older cancer survivors in particular, despite its promising impact on physiological and psychological function. Stress in particular has received very little research focus in older cancer survivors, but because the benefits of physical activity are so profound in older adults, it is an important and promising area of research.

\section{Conclusions and Future Directions}

Cancer-related stress affects all patients with cancer and negatively impacts cancer outcomes in terms of response to treatment, quality of life, disease progression, and survival in different phases of their experience. Feasibility of intervention with several CAM techniques and products commonly used by cancer patients and survivors has been established in some cancer populations: for example, mind-body techniques of meditation, yoga, Tai Chi Chuan, acupuncture, manipulative techniques massage, energy-based polarity therapy and Reiki, and some natural products. Efficacy of some CAM techniques and products in reducing stress and/or stress-related symptoms in patients with cancer has been documented

(1) Mindfulness-based stress reduction program with components similar to yoga showed reduction of stress levels in population of breast cancer and prostate cancer patients and improvements in endocrine indices of stress were also reported. Some studies of yoga intervention have shown significant stress reduction while some have shown beneficial effects on symptoms associated with stress for example, fatigue, sleep disturbances, hot flashes, and quality of life. However, the majority of studies of yoga were conducted in small samples of patients and there was a wide range of the length of intervention. This area of mind-body intervention seems to be promising in cancer; however, lack of uniformity of the intervention program in terms of its length and content makes it difficult to compare study results. Larger study samples with the use of comparable intervention programs may be more conclusive.

(2) Acupuncture can relieve anxiety, fatigue, and distress associated with advanced cancer.

(3) Practice of Tai Chi Chuan may be helpful in improving quality of life.

(4) Some herbs like lemon balm may be used, long in the term for relieving stress. Most current research suggests that patients with high levels of stress benefit the most from herbal supplements; therefore, studies are needed to examine their efficacy as well as safety.

(5) Most research on vitamins and supplements conducted in noncancer patients show promise in relieving stress; further trials in cancer patients are needed to demonstrate the safety of vitamin B and D supplementation in cancer patients receiving treatment before testing their efficacy on psychological stress.

(6) Physical activity may be helpful in reducing anxiety and distress in cancer survivors; however, the role of anxiety in affecting physical activity should be given consideration while designing intervention studies in cancer population.

(7) Research on CAM therapies for stress in childhood cancers is insufficient. Several promising CAM therapies may help children with cancer manage emotional and physical distress related to cancer and its treatment after the safety and utility of such therapies has been established.

(8) Stress in older cancer survivors is an important and promising area that is desperately needed to be examined as older adults are at much greater risk of developing cancer than young adults. It is especially important since by the year $2030,70 \%$ of cancer patients will be elderly.

Although some CAM techniques/products could be integrated into cancer care, much more research is needed to confirm their efficacy. Moreover, the wide variety of study designs and types of interventions are an obstacle to reach effective conclusions. Additionally, there is a need to study mechanisms of action of various techniques and products using innovative designs such as research on the effects of CAM on apoptotic and angiogenesis pathways; this may be helpful in understanding tumor development and its progression and applying CAM as a part of personalized medicine to ensure cancer-free and better quality of life.

CAM is primarily used by cancer patients to relieve disease- and treatment-related side effects. Although many of the symptoms usually subside after treatment, CAM utilization could help maintain a symptom-free and good quality of life during cancer treatment. The word "stress" cannot be over emphasized when associated with cancer experience. Stress reported by cancer patients could potentially alert healthcare providers about the impending negative outcomes of cancer treatments. Most CAM techniques are relatively inexpensive, simple to administer or practice, and encompass the holistic nature of healing. CAM for stress management could restore a patient's sense of control, maintain quality of life, reduce risk of cancer recurrence, and minimize physician visits. The first prescription following a cancer-related visit with a healthcare provider may be for stress management technique/product. Further research on CAM and stress can help healthcare professionals as well as patients with their understanding of the significance of safe use of integrative modes of treatment, better compliance with conventional treatment, improve treatment outcomes and survival, and possibly reduce the risk of recurrence of cancer. Thus, CAM 
for stress management could be a critical component of cancer care.

\section{Acknowledgments}

The authors would like to thank Dr. Joseph Roscoe and Dr. Susan Rosenthal for their support of this project and their suggestions regarding this paper. This paper was supported by grant NCI R25CA102618.

\section{References}

[1] NCCN, Distress management version 1.2011, http://www .nccn.org/professionals/physician_gls/pdf/distress.pdf, 2011.

[2] J. V. Pasacreta and M. Pickett, "Psychosocial aspects of palliative care," Seminars in oncology nursing, vol. 14, no. 2, pp. 110-120, 1998.

[3] D. E. Bailey Jr, M. Wallace, and M. H. Mishel, "Watching, waiting and uncertainty in prostate cancer," Journal of Clinical Nursing, vol. 16, no. 4, pp. 734-741, 2007.

[4] B. B. Germino, M. H. Mishel, M. Belyea, L. Harris, A. Ware, and J. Mohler, "Uncertainty in prostate cancer: ethnic and family patterns," Cancer Practice, vol. 6, no. 2, pp. 107-113, 1998.

[5] M. H. Mishel, B. B. Germino, L. Lin et al., "Managing uncertainty about treatment decision making in early stage prostate cancer: a randomized clinical trial," Patient Education and Counseling, vol. 77, no. 3, pp. 349-359, 2009.

[6] M. H. Mishel and D. S. Sorenson, "Uncertainty in gynecological cancer: a test of the mediating functions of mastery and coping," Nursing Research, vol. 40, no. 3, pp. 167-171, 1991.

[7] N. K. Aaronson, B. E. Meyerowitz, M. Bard et al., "Quality of life research in oncology. Past achievements and future priorities," Cancer, vol. 67, supplement 3, pp. 839-843, 1991.

[8] W. H. Redd, P. M. Silberfarb, B. L. Andersen et al., "Physiologic and psychobehavioral research in oncology," Cancer, vol. 67, no. 3, pp. 813-822, 1991.

[9] D. Spiegel, "Psychosocial aspects of breast cancer treatment," Seminars in Oncology, vol. 24, no. 1, pp. S1-S1, 1997.

[10] P. Herschbach, M. Keller, L. Knight et al., "Psychological problems of cancer patients: a cancer distress screening with a cancer-specific questionnaire," British Journal of Cancer, vol. 91, no. 3, pp. 504-511, 2004.

[11] C. S. Cleeland, T. R. Mendoza, X. S. Wang et al., "Assessing symptom distress in cancer patients: the M.D. Anderson Symptom inventory," Cancer, vol. 89, no. 7, pp. 1634-1646, 2000.

[12] Y. Wengstrom, C. Häggmark, H. Strander, and C. Forsberg, "Perceived symptoms and quality of life in women with breast cancer receiving radiation therapy," European Journal of Oncology Nursing, vol. 4, no. 2, pp. 78-88, 2000.

[13] M. Ewertz and A. B. Jensen, "Late effects of breast cancer treatment and potentials for rehabilitation," Acta Oncologica, vol. 50, no. 2, pp. 187-193, 2011.

[14] W. Gao, M. I. Bennett, D. Stark, S. Murray, and I. J. Higginson, "Psychological distress in cancer from survivorship to end of life care: prevalence, associated factors and clinical implications," European Journal of Cancer, vol. 46, no. 11, pp. 2036-2044, 2010.

[15] J. P. Solano, B. Gomes, and I. J. Higginson, "A comparison of symptom prevalence in far advanced cancer, AIDS, heart disease, chronic obstructive pulmonary disease and renal disease," Journal of Pain and Symptom Management, vol. 31, no. 1, pp. 58-69, 2006.

[16] L. E. Carlson, S. L. Groff, O. Maciejewski, and B. D. Bultz, "Screening for distress in lung and breast cancer outpatients: a randomized controlled trial," Journal of Clinical Oncology, vol. 28, no. 33, pp. 4884-4891, 2010.

[17] G. Van der Pompe, H. J. Duivenvoorden, M. H. Antoni, A. Visser, and C. J. Heijnen, "Effectiveness of a short-term group psychotherapy program on endocrine and immune function in breast cancer patients: an exploratory study," Journal of Psychosomatic Research, vol. 42, no. 5, pp. 453-466, 1997.

[18] M. H. Antoni, S. R. Wimberly, S. C. Lechner et al., "Reducion of cancer-specific though intrusuions and anxiety symptoms with a stress management intervention among women undergoing treatment for breast cancer," American Journal of Psychiatry, vol. 163, no. 10, pp. 1791-1797, 2006.

[19] D. G. Cruess, M. H. Antoni, B. A. McGregor et al., "Cognitive-behavioral stress management reduces serum cortisol by enhancing benefit finding among women being treated for early stage breast cancer," Psychosomatic Medicine, vol. 62, no. 3, pp. 304-308, 2000.

[20] K. M. Phillips, M. H. Antoni, S. C. Lechner et al., "Stress management intervention reduces serum cortisol and increases relaxation during treatment for nonmetastatic breast cancer," Psychosomatic Medicine, vol. 70, no. 9, pp. 1044-1049, 2008.

[21] L. E. Carlson, M. Speca, K. D. Patel, and E. Goodey, "Mindfulness-based stress reduction in relation to quality of life, mood, symptoms of stress and levels of cortisol, dehydroepiandrosterone sulfate (DHEAS) and melatonin in breast and prostate cancer outpatients," Psychoneuroendocrinology, vol. 29, no. 4, pp. 448-474, 2004.

[22] R. H. Matousek, J. C. Pruessner, and P. L. Dobkin, "Changes in the cortisol awakening response (CAR) following participation in Mindfulness-Based Stress Reduction in women who completed treatment for breast cancer," Complementary Therapies in Clinical Practice, vol. 17, no. 2, pp. 65-70, 2011.

[23] D. M. Eisenberg, R. C. Kessler, C. Foster, F. E. Norlock, D. R. Calkins, and T. L. Delbanco, "Unconventional medicine in the United States. Prevalence, costs, and patterns of use," New England Journal of Medicine, vol. 328, no. 4, pp. 246-252, 1993.

[24] P. J. Mansky and D. B. Wallerstedt, "Complementary medicine in palliative care and cancer symptom management," Cancer Journal, vol. 12, no. 5, pp. 425-431, 2006.

[25] V. E. von Gruenigen, H. E. Frasure, E. L. Jenison, M. P. Hopkins, and K. M. Gil, "Longitudinal assessment of quality of life and lifestyle in newly diagnosed ovarian cancer patients: the roles of surgery and chemotherapy," Gynecologic Oncology, vol. 103, no. 1, pp. 120-126, 2006.

[26] A. Baum, L. Cohen, and M. Hall, "Control and intrusive memories as possible determinants of chronic stress," Psychosomatic Medicine, vol. 55, no. 3, pp. 274-286, 1993.

[27] E. O. Johnson, T. C. Kamilaris, G. P. Chrousos, and P. W. Gold, "Mechanisms of stress: a dynamic overview of hormonal and behavioral homeostasis," Neuroscience and Biobehavioral Reviews, vol. 16, no. 2, pp. 115-130, 1992.

[28] K. Szemeredi, G. Bagdy, R. Stull, A. E. Calogero, I. J. Kopin, and D. S. Goldstein, "Sympathoadrenomedullary inhibition by chronic glucocorticoid treatment in conscious rats," Endocrinology, vol. 123, no. 5, pp. 2585-2590, 1988.

[29] P. J. Fitzgerald, "Is norepinephrine an etiological factor in some types of cancer?" International Journal of Cancer, vol. 124, no. 2, pp. 257-263, 2009. 
[30] K. S. R. Sastry, Y. Karpova, S. Prokopovich et al., "Epinephrine protects cancer cells from apoptosis via activation of cAMP-dependent protein kinase and BAD phosphorylation," Journal of Biological Chemistry, vol. 282, no. 19, pp. 14094-14100, 2007.

[31] G. Van der Pompe, M. H. Antoni, and C. J. Heijnen, "Elevated basal cortisol levels and attenuated ACTH and cortisol responses to a behavioral challenge in women with metastatic breast cancer," Psychoneuroendocrinology, vol. 21, no. 4, pp. 361-374, 1996.

[32] H. C. Abercrombie, J. Giese-Davis, S. Sephton, E. S. Epel, J. M. Turner-Cobb, and D. Spiegel, "Flattened cortisol rhythms in metastatic breast cancer patients," Psychoneuroendocrinology, vol. 29, no. 8, pp. 1082-1092, 2004.

[33] S. E. Sephton, R. M. Sapolsky, H. C. Kraemer, and D. Spiegel, "Diurnal cortisol rhythm as a predictor of breast cancer survival," Journal of the National Cancer Institute, vol. 92, no. 12, pp. 994-1000, 2000.

[34] B. W. Penninx, J. M. Guralnik, M. Pahor et al., "Chronically depressed mood and cancer risk in older persons," Journal of the National Cancer Institute, vol. 90, no. 24, pp. 1888-1893, 1998.

[35] M. Watson, J. S. Haviland, S. Greer, J. Davidson, and J. M. Bliss, "Influence of psychological response on survival in breast cancer: a population-based cohort study," The Lancet, vol. 354, no. 9187, pp. 1331-1336, 1999.

[36] M. Stommel, B. A. Given, and C. W. Given, "Depression and functional status as predictors of death among cancer patients," Cancer, vol. 94, no. 10, pp. 2719-2727, 2002.

[37] F. R. Loberiza, J. D. Rizzo, C. N. Bredeson et al., "Association of depressive syndrome and early deaths among patients after stem-cell transplantation for malignant diseases," Journal of Clinical Oncology, vol. 20, no. 8, pp. 2118-2126, 2002.

[38] B. Seruga, H. Zhang, L. J. Bernstein, and I. F. Tannock, "Cytokines and their relationship to the symptoms and outcome of cancer," Nature Reviews Cancer, vol. 8, no. 11, pp. 887-899, 2008.

[39] S. K. Lutgendorf, A. K. Sood, M. H. Antoni et al., "Host factors and cancer progression: biobehavioral signaling pathways and interventions," Journal of Clinical Oncology, vol. 28, no. 26, pp. 4094-4099, 2010.

[40] J. L. Ryan, J. K. Carroll, E. P. Ryan, K. M. Mustian, K. Fiscella, and G. R. Morrow, "Mechanisms of cancer-related fatigue," Oncologist, vol. 12, supplement 1, pp. 22-34, 2007.

[41] M. C. Janelsins, K. M. Mustian, O. G. Palesh et al., "Differential expression of cytokines in breast cancer patients receiving different chemotherapies: implications for cognitive impairment research," Supportive Care in Cancer, vol. 20, no. 4, pp. 831-9, 2012.

[42] J. E. Bower, P. A. Ganz, L. T. May et al., "Inflammatory biomarkers and fatigue during radiation therapy for breast and prostate cancer," Clinical Cancer Research, vol. 15, no. 17, pp. 5534-5540, 2009.

[43] J. E. Bower, P. A. Ganz, S. S. Dickerson, L. Petersen, N. Aziz, and J. L. Fahey, "Diurnal cortisol rhythm and fatigue in breast cancer survivors," Psychoneuroendocrinology, vol. 30, no. 1, pp. 92-100, 2005.

[44] J. E. Bower, P. A. Ganz, K. A. Desmond, J. H. Rowland, B. E. Meyerowitz, and T. R. Belin, "Fatigue in breast cancer survivors: occurrence, correlates, and impact on quality of life," Journal of Clinical Oncology, vol. 18, no. 4, pp. 743-753, 2000.

[45] G. D. Marshall Jr, "The adverse effects of psychological stress on immunoregulatory balance: applications to human inflammatory diseases," Immunology and Allergy Clinics of North America, vol. 31, no. 1, pp. 133-140, 2011.

[46] S. K. Agarwal and G. D. Marshall Jr, "Stress effects on immunity and its application to clinical immunology," Clinical and Experimental Allergy, vol. 31, no. 1, pp. 25-31, 2001.

[47] J. A. Moynihan, "Mechanisms of stress-induced modulation of immunity," Brain, Behavior, and Immunity, vol. 17, supplement 1, pp. S11-S16, 2003.

[48] E. M. V. Reiche, S. O. V. Nunes, and H. K. Morimoto, "Stress, depression, the immune system, and cancer," Lancet Oncology, vol. 5, no. 10, pp. 617-625, 2004.

[49] W. Wu, T. Yamaura, K. Murakami et al., "Social isolation stress enhanced liver metastasis of murine colon 26-L5 carcinoma cells by suppressing immune responses in mice," Life Sciences, vol. 66, no. 19, pp. 1827-1838, 2000.

[50] W. Wu, J. Murata, K. Hayashi, T. Yamaura, N. Mitani, and I. Saiki, "Social isolation stress impairs the resistance of mice to experimental liver metastasis of murine colon 26-L5 carcinoma cells," Biological and Pharmaceutical Bulletin, vol. 24, no. 7, pp. 772-776, 2001.

[51] I. Herr, E. Ucur, K. Herzer et al., "Glucocorticoid cotreatment induces apoptosis resistance toward cancer therapy in carcinomas," Cancer Research, vol. 63, no. 12, pp. 3112-3120, 2003.

[52] K. S. R. Sastry, Y. Karpova, S. Prokopovich et al., "Epinephrine protects cancer cells from apoptosis via activation of cAMP-dependent protein kinase and BAD phosphorylation," Journal of Biological Chemistry, vol. 282, no. 19, pp. 14094-14100, 2007.

[53] A. Bikfalvi, "Significance of angiogenesis in tumour progression and metastasis," European Journal of Cancer A, vol. 31, no. 7-8, pp. 1101-1104, 1995.

[54] J. M. Fredriksson, J. M. Lindquist, G. E. Bronnikov, and J. Nedergaard, "Norepinephrine induces vascular endothelial growth factor gene expression in brown adipocytes through a $\beta$-adrenoreceptor/cAMP/protein kinase A pathway involving Src but independently of Erk1/2," Journal of Biological Chemistry, vol. 275, no. 18, pp. 13802-13811, 2000.

[55] S. K. Lutgendorf, S. Cole, E. Costanzo et al., "Stressrelated mediators stimulate vascular endothelial growth factor secretion by two ovarian cancer cell lines," Clinical Cancer Research, vol. 9, no. 12, pp. 4514-4521, 2003.

[56] E. V. Yang, E. L. Donovan, D. M. Benson, and R. Glaser, "VEGF is differentially regulated in multiple myelomaderived cell lines by norepinephrine," Brain, Behavior, and Immunity, vol. 22, no. 3, pp. 318-323, 2008.

[57] P. H. Thaker, L. Y. Han, A. A. Kamat et al., "Chronic stress promotes tumor growth and angiogenesis in a mouse model of ovarian carcinoma," Nature Medicine, vol. 12, no. 8, pp. 939-944, 2006.

[58] E. V. Yang, A. K. Sood, M. Chen et al., "Norepinephrine up-regulates the expression of vascular endothelial growth factor, matrix metalloproteinase (MMP)-2, and MMP-9 in nasopharyngeal carcinoma tumor cells," Cancer Research, vol. 66, no. 21, pp. 10357-10364, 2006.

[59] NCCAM, Expanding Horizons of Health Care Strategic Plan 2005-2009, National Center for Complementary and Alternative Medicine, Gaithersburg, Md, USA, 2004.

[60] E. Ernst, "The current position of complementary/alternative medicine in cancer," European Journal of Cancer, vol. 39, no. 16, pp. 2273-2277, 2003.

[61] J. M. Fouladbakhsh and M. Stommel, "Gender, symptom experience, and use of complementary and alternative 
medicine practices among cancer survivors in the U.S. cancer population," Oncology Nursing Forum, vol. 37, no. 1, pp. E7E15, 2010.

[62] C. Buettner, C. H. Kroenke, R. S. Phillips, R. B. Davis, D. M. Eisenberg, and M. D. Holmes, "Correlates of use of different types of complementary and alternative medicine by breast cancer survivors in the nurses' health study," Breast Cancer Research and Treatment, vol. 100, no. 2, pp. 219-227, 2006.

[63] D. A. Monti and J. Yang, "Complementary medicine in chronic cancer care," Seminars in Oncology, vol. 32, no. 2, pp. 225-231, 2005.

[64] K. D. Stein, C. Kaw, C. Crammer, and T. Gansler, "The role of psychological functioning in the use of complementary and alternative methods among disease-free colorectal cancer survivors: a report from the American cancer society's studies of cancer survivors," Cancer, vol. 115, supplement 18, pp. 4397-4408, 2009.

[65] S. M. Alferi, M. H. Antoni, G. Ironson, K. M. Kilbourn, and C. S. Carver, "Factors predicting the use of complementary therapies in a multi-ethnic sample of early-stage breast cancer patients," Journal of the American Medical Women's Association, vol. 56, no. 3, pp. 120-126, 2001.

[66] L. A. Hjelle, "Transcendental meditation and psychological health," Perceptual and Motor Skills, vol. 39, no. 1, pp. 623628, 1974.

[67] M. E. McIntyre, F. H. Silverman, and W. D. Trotter, "Transcendental meditation and stuttering: a preliminary report," Perceptual and Motor Skills, vol. 39, no. 1, 1974.

[68] D. W. Orme-Johnson, "Autonomic stability and transcendental meditation," Psychosomatic Medicine, vol. 35, no. 4, pp. 341-349, 1973.

[69] R. K. Wallace, "Physiological effects of transcendental meditation," Science, vol. 167, no. 3926, pp. 1751-1754, 1970.

[70] J. Kabat-Zinn, "An outpatient program in behavioral medicine for chronic pain patients based on the practice of mindfulness meditation: theoretical considerations and preliminary results," General Hospital Psychiatry, vol. 4, no. 1, pp. 33-47, 1982.

[71] V. S. Eschiti, "Lesson from comparison of CAM use by women with female-specific cancers to others: it's time to focus on interaction risks with CAM therapies," Integrative Cancer Therapies, vol. 6, no. 4, pp. 313-344, 2007.

[72] H. Greenlee, M. L. Kwan, I. J. Ergas et al., "Complementary and alternative therapy use before and after breast cancer diagnosis: the pathways study," Breast Cancer Research and Treatment, vol. 117, no. 3, pp. 653-665, 2009.

[73] J. Banasik, H. Williams, M. Haberman, S. E. Blank, and R. Bendel, "Effect of Iyengar yoga practice on fatigue and diurnal salivary cortisol concentration in breast cancer survivors," Journal of the American Academy of Nurse Practitioners, vol. 23, no. 3, pp. 135-142, 2011.

[74] L. E. Carlson, M. Speca, P. Faris, and K. D. Patel, "One year pre-post intervention follow-up of psychological, immune, endocrine and blood pressure outcomes of mindfulnessbased stress reduction (MBSR) in breast and prostate cancer outpatients," Brain, Behavior, and Immunity, vol. 21, no. 8, pp. 1038-1049, 2007.

[75] J. W. Carson, K. M. Carson, L. S. Porter, F. J. Keefe, and V. L. Seewaldt, "Yoga of Awareness program for menopausal symptoms in breast cancer survivors:r from a randomized trial," Supportive Care in Cancer, vol. 17, no. 10, pp. 13011309, 2009.
[76] S. C. Danhauer, S. L. Mihalko, G. B. Russell et al., "Restorative yoga for women with breast cancer: finding from a randomized pilot study," Psycho-Oncology, vol. 18, no. 4, pp. 360-368, 2009.

[77] C. A. Lengacher, M. P. Bennett, K. E. Kip, L. Gonzalez, P. Jacobsen, and C. E. Cox, "Relief of symptoms, side effects, and psychological distress through use of complementary and alternative medicine in women with breast cancer," Oncology Nursing Forum, vol. 33, no. 1, pp. 97-104, 2006.

[78] C. A. Lengacher, V. Johnson-Mallard, J. Post-White et al., "Randomized controlled trial of mindfulness-based stress reduction (MBSR) for survivors of breast cancer," PsychoOncology, vol. 18, no. 12, pp. 1261-1272, 2009.

[79] A. Moadel, C. Morgan, A. Fatone et al., "Seeking meaning and hope: self-reported spiritual and existential needs among an ethnically-diverse cancer patient population," Psycho Oncology, vol. 8, no. 5, pp. 378-385, 1999.

[80] K. D. Chandwani, B. Thornton, G. H. Perkins et al., "Yoga improves quality of life and benefit finding in women undergoing radiotherapy for breast cancer," Journal of the Society for Integrative Oncology, vol. 8, no. 2, pp. 43-55, 2010.

[81] L. E. Carlson, M. Speca, K. D. Patel, and E. Goodey, "Mindfulness-based stress reduction in relation to quality of life, mood, symptoms of stress and levels of cortisol, dehydroepiandrosterone sulfate (DHEAS) and melatonin in breast and prostate cancer outpatients," Psychoneuroendocrinology, vol. 29, no. 4, pp. 448-474, 2004.

[82] M. Speca, L. E. Carlson, E. Goodey, and M. Angen, "A randomized, wait-list controlled clinical trial: the effect of a mindfulness meditation-based stress reduction program on mood and symptoms of stress in cancer outpatients," Psychosomatic Medicine, vol. 62, no. 5, pp. 613-622, 2000.

[83] L. E. Carlson and S. N. Garland, "Impact of mindfulnessbased stress reduction (MBSR) on sleep, mood, stress and fatigue symptoms in cancer outpatients," International Journal of Behavioral Medicine, vol. 12, no. 4, pp. 278-285, 2005.

[84] B. Banerjee, H. S. Vadiraj, A. Ram et al., "Effects of an integrated yoga program in modulating psychological stress and radiation-induced genotoxic stress in breast cancer patients undergoing radiotherapy," Integrative Cancer Therapies, vol. 6, no. 3, pp. 242-250, 2007.

[85] J. W. Carson, K. M. Carson, L. S. Porter, F. J. Keefe, H. Shaw, and J. M. Miller, "Yoga for women with metastatic breast cancer: results from a pilot study," Journal of Pain and Symptom Management, vol. 33, no. 3, pp. 331-341, 2007.

[86] L. Cohen, C. Warneke, R. T. Fouladi, M. A. Rodriguez, and A. Chaoul-Reich, "Psychological adjustment and sleep quality in a randomized trial of the effects of a tibetan yoga intervention in patients with lymphoma," Cancer, vol. 100, no. 10, pp. 2253-2260, 2004.

[87] S. N. Culos-Reed, L. E. Carlson, L. M. Daroux, and S. HatelyAldous, "A pilot study of yoga for breast cancer survivors: physical and psychological benefits," Psycho-Oncology, vol. 15, no. 10, pp. 891-897, 2006.

[88] S. C. Danhauer, J. A. Tooze, D. F. Farmer et al., "Restorative yoga for women with ovarian or breast cancer: findings from a pilot study," Journal of the Society for Integrative Oncology, vol. 6, no. 2, pp. 47-58, 2008.

[89] C. D. Joseph, "Psychological supportive therapy for cancer patients," Indian Journal of Cancer, vol. 20, no. 5, pp. 268270, 1983. 
[90] A. B. Moadel, C. Shah, J. Wylie-Rosett et al., "Randomized controlled trial of yoga among a multiethnic sample of breast cancer patients: effects on quality of life," Journal of Clinical Oncology, vol. 25, no. 28, pp. 4387-4395, 2007.

[91] R. M. Raghavendra, R. Nagarathna, H. R. Nagendra et al., "Effects of an integrated yoga programme on chemotherapyinduced nausea and emesis in breast cancer patients," European Journal of Cancer Care, vol. 16, no. 6, pp. 462-474, 2007.

[92] M. R. Rao, N. Raghuram, H. R. Nagendra et al., "Anxiolytic effects of a yoga program in early breast cancer patients undergoing conventional treatment: a randomized controlled trial," Complementary Therapies in Medicine, vol. 17, no. 1, pp. 1-8, 2009.

[93] R. M. Rao, S. Telles, H. R. Nagendra et al., "Effects of yoga on natural killer cell counts in early breast cancer patients undergoing conventional treatment. Comment to: recreational music-making modulates natural killer cell activity, cytokines, and mood states in corporate employees Masatada Wachi, Masahiro Koyama, Masanori Utsuyama, Barry B. Bittman, Masanobu Kitagawa, Katsuiku Hirokawa Med Sci Monit, 2007, 13(2): CR57-70," Medical Science Monitor, vol. 14, no. 2, pp. LE3-LE4.

[94] E. Rosenbaum, H. Gautier, P. Fobair et al., "Cancer supportive care, improving the quality of life for cancer patients. A program evaluation report," Supportive Care in Cancer, vol. 12, no. 5, pp. 293-301, 2004.

[95] H. S. Vadiraja, R. M. Raghavendra, R. Nagarathna et al., "Effects of a Yoga program on cortisol rhythm and mood states in early breast cancer patients undergoing adjuvant radiotherapy: a randomized controlled trial," Integrative Cancer Therapies, vol. 8, no. 1, pp. 37-46, 2009.

[96] A. E. Speed-Andrews, C. Stevinson, L. J. Belanger, J. J. Mirus, and K. S. Courneya, "Pilot evaluation of an Iyengar yoga program for breast cancer survivors," Cancer Nursing, vol. 33, no. 5, pp. 369-381, 2010.

[97] K. M. Mustian, O. Palesh, L. Sprod et al., "Effect of YOCAS yoga on sleep, fatigue, and quality of life: a URCC CCOP randomized, controlled clinical trial among 410 cancer survivors," in Proceedings of the 2010 ASCO Annual Meeting, Chicago, Ill, USA, 2010.

[98] K. M. Mustian, O. Palesh, L. Sprod et al., "Effect of YOCAS yoga on circadian rhythm, anxiety, and mood: a URCC CCOP randomized, controlled clinical trial among 410 cancer survivors," in Proceedings of the 2010 ASCO Annual Meeting, Chicago, Ill, USA, 2011.

[99] T. Kovacic and M. Kovacic, "Impact of relaxation training according to Yoga in Daily Life $($ ) system on perceived stress after breast cancer surgery," Integrative Cancer Therapies, vol. 10, no. 1, pp. 16-26, 2011.

[100] P. Mansky, T. Sannes, D. Wallerstedt et al., "Tai chi chuan: mind-body practice or exercise intervention? Studying the benefit for cancer survivors," Integrative Cancer Therapies, vol. 5, no. 3, pp. 192-201, 2006.

[101] M. C. Janelsins, P. G. Davis, L. Wideman et al., "Effects of Tai Chi Chuan on insulin and cytokine levels in a randomized controlled pilot study on breast cancer survivors.", Clinical Breast Cancer, vol. 11, no. 3, pp. 161-170, 2011.

[102] K. M. Mustian, J. A. Katula, D. L. Gill, J. A. Roscoe, D. Lang, and K. Murphy, "Tai Chi Chuan, health-related quality of life and self-esteem: a randomized trial with breast cancer survivors," Supportive Care in Cancer, vol. 12, no. 12, pp. 871876, 2004.
[103] K. M. Mustian, J. A. Katula, and H. Zhao, "A pilot study to assess the influence of Tai Chi Chuan on functional capacity among breast cancer survivors," Journal of Supportive Oncology, vol. 4, no. 3, pp. 139-145, 2006.

[104] K. Mustian, O. Palesh, and S. Flecksteiner, "Tai Chi Chuan for breast cancer survivors," Medicine and Sport Science, vol. 52, pp. 209-217, 2008.

[105] L. J. Peppone, K. M. Mustian, M. C. Janelsins et al., "Effects of a structured weight-bearing exercise program on bone metabolism among breast cancer survivors: a feasibility trial," Clinical Breast Cancer, vol. 10, no. 3, pp. 224-229, 2010.

[106] K. M. Mustian, J. A. Roscoe, G. R. Morrow, O. G. Palesh, and S. Kohli, "Tai Chi Chuan, immune function, and cardiorespiratory fitness among breast cancer survivors," Annals of Behavioral Medicine, vol. 33, p. 95, 2007.

[107] T. S. Pavão, P. Vianna, M. M. Pillat, A. B. Machado, and M. E. Bauer, "Acupuncture is effective to attenuate stress and stimulate lymphocyte proliferation in the elderly," Neuroscience Letters, vol. 484, no. 1, pp. 47-50, 2010.

[108] E. Dean-Clower, A. M. Doherty-Gilman, A. Keshaviah et al., "Acupuncture as palliative therapy for physical symptoms and quality of life for advanced cancer patients," Integrative Cancer Therapies, vol. 9, no. 2, pp. 158-167, 2010.

[109] J. Finnegan-John, A. Molassiotis, A. Richardson, and E. Ream, "A systematic review of complementary and Alternative medicine interventions in the management of cancerrelated fatigue," BMJ Support Palliat Care, vol. 1, p. A12, 2011.

[110] E. M. Walker, A. I. Rodriguez, B. Kohn et al., "Acupuncture versus venlafaxine for the management of vasomotor symptoms in patients with hormone receptor-positive breast cancer: a randomized controlled trial," Journal of Clinical Oncology, vol. 28, no. 4, pp. 634-640, 2010.

[111] B. A. de Valois, T. E. Young, N. Robinson, C. McCourt, and E. J. Maher, "Using traditional acupuncture for breast cancerrelated hot flashes and night sweats," Journal of Alternative and Complementary Medicine, vol. 16, no. 10, pp. 1047-1057, 2010.

[112] D. O’Regan and J. Filshie, "Acupuncture and cancer," Autonomic Neuroscience, vol. 157, no. 1-2, pp. 96-100, 2010.

[113] G. H. Montgomery, M. Kangas, D. David et al., "Fatigue during breast cancer radiotherapy: an initial randomized study of cognitive-behavioral therapy plus hypnosis," Health Psychology, vol. 28, no. 3, pp. 317-322, 2009.

[114] G. H. Montgomery, D. H. Bovbjerg, J. B. Schnur et al., "A randomized clinical trial of a brief hypnosis intervention to control side effects in breast surgery patients," Journal of the National Cancer Institute, vol. 99, no. 17, pp. 1304-1312, 2007.

[115] E. Ernst, "Herbal remedies for anxiety-a systematic review of controlled clinical trials," Phytomedicine, vol. 13, no. 3, pp. 205-208, 2006.

[116] S. A. Saeed, R. M. Bloch, and D. J. Antonacci, "Herbal and dietary supplements for treatment of anxiety disorders," American Family Physician, vol. 76, no. 4, pp. 549-556, 2007.

[117] G. Van der Watt, J. Laugharne, and A. Janca, "Complementary and alternative medicine in the treatment of anxiety and depression," Current Opinion in Psychiatry, vol. 21, no. 1, pp. 37-42, 2008.

[118] A. Naing, S. K. Stephen, M. Frenkel et al., "Prevalence of complementary medicine use in a phase 1 clinical trials program: the MD Anderson cancer center experience," Cancer, vol. 117, no. 22, pp. 5142-5150, 2011. 
[119] F. Qi, A. Li, Y. Inagaki et al., "Chinese herbal medicines as adjuvant treatment during chemo- or radio-therapy for cancer," Bioscience trends, vol. 4, no. 6, pp. 297-307, 2010.

[120] D. O. Kennedy, W. Little, C. F. Haskell, and A. B. Scholey, "Anxiolytic effects of a combination of Melissa officinalis and Valeriana officinalis during laboratory induced stress," Phytotherapy Research, vol. 20, no. 2, pp. 96-102, 2006.

[121] S. F. Muller and S. Klement, "A combination of valerian and lemon balm is effective in the treatment of restlessness and dyssomnia in children," Phytomedicine, vol. 13, no. 6, pp. 383-387, 2006.

[122] B. S. Weeks, "Formulations of dietary supplements and herbal extracts for relaxation and anxiolytic action: relarian," Medical Science Monitor, vol. 15, no. 11, pp. RA256-RA262, 2009.

[123] G. Mark, Herbal supplement for stress, http://www.livestrong .com/article/15705-herbal-supplement-for-stress/, 2010.

[124] K. Soden, K. Vincent, S. Craske, C. Lucas, and S. Asley, "A randomized controlled trial of aromatherapy massage in a hospice setting," Palliative Medicine, vol. 18, no. 2, pp. 87-92, 2004.

[125] D. Wheatley, "Kava and valerian in the treatment of stressinduced insomnia," Phytotherapy Research, vol. 15, no. 6, pp. 549-551, 2001.

[126] S. Akhondzadeh, H. R. Naghavi, M. Vazirian, A. Shayeganpour, H. Rashidi, and M. Khani, "Passionflower in the treatment of generalized anxiety: a pilot double-blind randomized controlled trial with oxazepam," Journal of Clinical Pharmacy and Therapeutics, vol. 26, no. 5, pp. 363-367, 2001.

[127] F. M. Painter, "Panax ginseng. Monograph," Alternative Medicine Review, vol. 14, no. 2, pp. 172-176, 2009.

[128] G. S. Kienle and H. Kiene, "Influence of viscum album L (European Mistletoe) extracts on quality of life in cancer patients: a systematic review of controlled clinical studies," Integrative Cancer Therapies, vol. 9, no. 2, pp. 142-157, 2010.

[129] J. L. Reay, D. O. Kennedy, and A. B. Scholey, "Effects of Panax ginseng, consumed with and without glucose, on blood glucose levels and cognitive performance during sustained 'mentally demanding' tasks," Journal of Psychopharmacology, vol. 20, no. 6, pp. 771-781, 2006.

[130] S. Nechuta, W. Lu, Z. Chen et al., "Vitamin supplement use during breast cancer treatment and survival: a prospective cohort study," Cancer Epidemiology, Biomarkers \& Prevention, vol. 20, no. 2, pp. 262-271, 2011

[131] H. Greenlee, M.L. Kwan, L.H. Kushi et al., "Antioxidant supplement use after breast cancer diagnosis and mortality in the life after cancer epidemiology (LACE) cohort," Cancer, vol. 118, no. 8, pp. 2048-2058, 2012.

[132] C. M. Velicer and C. M. Ulrich, "Vitamin and mineral supplement use among US adults after cancer diagnosis: a systematic review," Journal of Clinical Oncology, vol. 26, no. 4, pp. 665-673, 2008.

[133] C. Van Guldener and C. D. A. Stehouwer, "Homocysteinelowering treatment: an overview," Expert Opinion on Pharmacotherapy, vol. 2, no. 9, pp. 1449-1460, 2001.

[134] O. P. Almeida, K. McCaul, G. J. Hankey, P. Norman, K. Jamrozik, and L. Flicker, "Homocysteine and depression in later life," Archives of General Psychiatry, vol. 65, no. 11, pp. 1286-1294, 2008

[135] M. W. P. Carney, T. K. N. Chary, M. Laundy et al., "Red cell folate concentrations in psychiatric patients," Journal of Affective Disorders, vol. 19, no. 3, pp. 207-213, 1990.

[136] M. T. Coppen and A. Abou-Saleh, "Plasma folate and affective morbidity during long-term lithium therapy," The British Journal of Psychiatry, vol. 141, pp. 87-89, 1982.

[137] M. S. Morris, M. Fava, P. F. Jacques, J. Selhub, and I. H. Rosenberg, "Depression and folate status in the US population," Psychotherapy and Psychosomatics, vol. 72, no. 2, pp. 80-87, 2003.

[138] M. W. P. Carney and B. F. Sheffield, "Serum folic acid and B12 in 272 psychiatric in-patients," Psychological Medicine, vol. 8, no. 1, pp. 139-144, 1978.

[139] H. Tiemeier, H. Ruud van Tuijl, A. Hofman, J. Meijer, A. J. Kiliaan, and M. M. B. Breteler, "Vitamin B12, folate, and homocysteine in depression: the Rotterdam study," American Journal of Psychiatry, vol. 159, no. 12, pp. 2099-2101, 2002.

[140] B. W. Penninx, J. M. Guralnik, L. Ferrucci, L. P. Fried, R. H. Allen, and S. P. Stabler, "Vitamin B12 deficiency and depression in physically disabled older women: epidemiologic evidence from the women's health and aging study," American Journal of Psychiatry, vol. 157, no. 5, pp. 715-721, 2000.

[141] A. M. Hvas, S. Juul, P. Bech, and E. Nexø, "Vitamin B6 level is associated with symptoms of depression," Psychotherapy and Psychosomatics, vol. 73, no. 6, pp. 340-343, 2004.

[142] C. Merete, L. M. Falcon, and K. L. Tucker, "Vitamin B6 is associated with depressive symptomatology in Massachusetts elders," Journal of the American College of Nutrition, vol. 27, no. 3, pp. 421-427, 2008.

[143] J. E. Alpert, D. Mischoulon, G. Rubenstein, K. Bottonari, A. Nierenberg, and M. Fava, "Folinic acid (Leucovorin) as an adjunctive treatment for SSRI-refractory depression," Annals of Clinical Psychiatry, vol. 14, no. 1, pp. 33-38, 2002.

[144] A. Coppen and J. Bailey, "Enhancement of the antidepressant action of fluoxetine by folic acid: a randomised, placebo controlled trial," Journal of Affective Disorders, vol. 60, no. 2, pp. 121-130, 2000.

[145] P. S. A. Godfrey, B. K. Toone, M. W. P. Carney et al., "Enhancement of recovery from psychiatric illness by methylfolate," The Lancet, vol. 336, no. 8712, pp. 392-395, 1990.

[146] E. Garcion, N. Wion-Barbot, C. N. Montero-Menei, F. Berger, and D. Wion, "New clues about vitamin D functions in the nervous system," Trends in Endocrinology and Metabolism, vol. 13, no. 3, pp. 100-105, 2002.

[147] D. Eyles, J. Brown, A. Mackay-Sim, J. McGrath, and F. Feron, "Vitamin D3 and brain development," Neuroscience, vol. 118, no. 3, pp. 641-653, 2003.

[148] D. J. Armstrong, G. K. Meenagh, I. Bickle, A. S. H. Lee, E. S. Curran, and M. B. Finch, "Vitamin D deficiency is associated with anxiety and depression in fibromyalgia," Clinical Rheumatology, vol. 26, no. 4, pp. 551-554, 2007.

[149] R. J. Przybelski and N. C. Binkley, "Is vitamin D important for preserving cognition? A positive correlation of serum 25hydroxyvitamin D concentration with cognitive function," Archives of Biochemistry and Biophysics, vol. 460, no. 2, pp. 202-205, 2007.

[150] C. H. Wilkins, Y. I. Sheline, C. M. Roe, S. J. Birge, and J. C. Morris, "Vitamin D deficiency is associated with low mood and worse cognitive performance in older adults," American Journal of Geriatric Psychiatry, vol. 14, no. 12, pp. 1032-1040, 2006.

[151] R. Jorde, M. Sneve, Y. Figenschau, J. Svartberg, and K. Waterloo, "Effects of vitamin D supplementation on symptoms of depression in overweight and obese subjects: randomized double blind trial," Journal of Internal Medicine, vol. 264, no. 6, pp. 599-609, 2008.

[152] D. Schlager, J. E. Schwartz, and E. J. Bromet, "Seasonal variations of current symptoms in a healthy population," British Journal of Psychiatry, vol. 163, pp. 322-326, 1993.

[153] F. M. Gloth, W. Alam, and B. Hollis, "Vitamin D vs broad spectrum phototherapy in the treatment of Seasonal 
Affective Disorder," Journal of Nutrition, Health and Aging, vol. 3, no. 1, pp. 5-7, 1999.

[154] A. T. Lansdowne and S. C. Provost, "Vitamin D3 enhances mood in healthy subjects during winter," Psychopharmacology, vol. 135, no. 4, pp. 319-323, 1998.

[155] S. C. Gupta, J. H. Kim, R. Kannappan, S. Reuter, P. M. Dougherty, and B. B. Aggarwal, "Role of nuclear factorkappaB-mediated inflammatory pathways in cancer-related symptoms and their regulation by nutritional agents," Experimental Biology and Medicine, vol. 236, no. 6, pp. 658-671, 2011.

[156] R. Koto, M. Imamura, C. Watanabe et al., "Linalyl acetate as a major ingredient of lavender essential oil relaxes the rabbit vascular smooth muscle through dephosphorylation of myosin light chain," Journal of Cardiovascular Pharmacology, vol. 48, no. 1, pp. 850-856, 2006.

[157] J. Drozd and E. Anuszewska, "The effect of the Melissa officinalis extract on immune response in mice," Acta Poloniae Pharmaceutica, vol. 60, no. 6, pp. 467-470, 2003.

[158] D. Ivanova, D. Gerova, T. Chervenkov, and T. Yankova, "Polyphenols and antioxidant capacity of Bulgarian medicinal plants," Journal of Ethnopharmacology, vol. 96, no. 1-2, pp. 145-150, 2005.

[159] B. Marongiu, S. Porcedda, A. Piras, A. Rosa, M. Deiana, and M. A. Dessí, "Antioxidant activity of supercritical extract of Melissa officinalis subsp. officinalis and Melissa officinalis subsp. inodora," Phytotherapy Research, vol. 18, no. 10, pp. 789-792, 2004.

[160] V. Butterweck, "Mechanism of action of St John's wort in depression: what is known?" CNS Drugs, vol. 17, no. 8, pp. 539-562, 2003.

[161] D. Benke, A. Barberis, S. Kopp et al., "GABAA receptors as in vivo substrate for the anxiolytic action of valerenic acid, a major constituent of valerian root extracts," Neuropharmacology, vol. 56, no. 1, pp. 174-181, 2009.

[162] S. M. Elsas, D. J. Rossi, J. Raber et al., "Passiflora incarnata L. (Passionflower) extracts elicit GABA currents in hippocampal neurons in vitro, and show anxiogenic and anticonvulsant effects in vivo, varying with extraction method," Phytomedicine, vol. 17, no. 12, pp. 940-949, 2010.

[163] P. Hegde, M.S. Maddur, A. Friboulet, J. Bayry, and S.V. Kaveri, "Viscum album exerts anti-inflammatory effect by selectively inhibiting cytokine-induced expression of cyclooxygenase-2," PLoS ONE, vol. 6, no. 10, Article ID e26312, 2011.

[164] A. Billhult, C. Lindholm, R. Gunnarsson, and E. StenerVictorin, "The effect of massage on immune function and stress in women with breast cancer-a randomized controlled trial," Autonomic Neuroscience, vol. 150, no. 1-2, pp. 111-115, 2009.

[165] M. Listing, M. Krohn, C. Liezmann et al., "The efficacy of classical massage on stress perception and cortisol following primary treatment of breast cancer," Archives of Women's Mental Health, vol. 13, no. 2, pp. 165-173, 2010.

[166] A. Moraska, R. A. Pollini, K. Boulanger, M. Z. Brooks, and L. Teitlebaum, "Physiological adjustments to stress measures following massage therapy: a review of the literature," Evid Based Complement Alternat Med, vol. 7, no. 4, pp. 409-418, 2010.

[167] A. G. Taylor, D. I. Galper, P. Taylor et al., "Effects of adjunctive Swedish massage and vibration therapy on shortterm postoperative outcomes: a randomized, controlled trial," Journal of Alternative and Complementary Medicine, vol. 9, no. 1, pp. 77-89, 2003.

[168] J. A. Roscoe, S. E. Matteson, K. M. Mustian, D. Padmanaban, and G. R. Morrow, "Treatment of radiotherapy-induced fatigue through a nonpharmacological approach," Integrative Cancer Therapies, vol. 4, no. 1, pp. 8-13, 2005.

[169] K. M. Mustian, J. A. Roscoe, O. G. Palesh et al., "Polarity therapy for cancer-related fatigue in patients with breast cancer receiving radiation therapy: a randomized controlled pilot study," Integrative Cancer Therapies, vol. 10, no. 1, pp. 27-37, 2011.

[170] L. Korn, R. G. Logsdon, N. L. Polissar, A. Gomez-Beloz, T. Waters, and R. Rÿser, "A randomized trial of a cam therapy for stress reduction in American Indian and Alaskan native family caregivers," Gerontologist, vol. 49, no. 3, pp. 368-377, 2009.

[171] K. Olson, J. Hanson, and M. Michaud, "A phase II trial of Reiki for the management of pain in advanced cancer patients," Journal of Pain and Symptom Management, vol. 26, no. 5, pp. 990-997, 2003.

[172] K. L. Tsang, L. E. Carlson, and K. Olson, "Pilot crossover trial of Reiki versus rest for treating cancer-related fatigue," Integrative Cancer Therapies, vol. 6, no. 1, pp. 25-35, 2007.

[173] S. B. Hanser, S. Bauer-Wu, L. Kubicek et al., "Effects of a music therapy intervention on quality of life and distress in women with metastatic breast cancer," Journal of the Society for Integrative Oncology, vol. 4, no. 3, pp. 116-124, 2006.

[174] D. S. Burns, F. Azzouz, R. Sledge et al., "Music imagery for adults with acute leukemia in protective environments: a feasibility study," Supportive Care in Cancer, vol. 16, no. 5, pp. 507-513, 2008.

[175] P. Salmon, "Effects of physical exercise on anxiety, depression, and sensitivity to stress: a unifying theory," Clinical Psychology Review, vol. 21, no. 1, pp. 33-61, 2001.

[176] A. Tsatsoulis and S. Fountoulakis, "The protective role of exercise on stress system dysregulation and comorbidities," Annals of the New York Academy of Sciences, vol. 1083, pp. 196-213, 2006.

[177] J. Midtgaard, M. Rørth, R. Stelter et al., "The impact of a multidimensional exercise program on self-reported anxiety and depression in cancer patients undergoing chemotherapy: a phase II study," Palliative \& Supportive Care, vol. 3, no. 3, pp. 197-208, 2005.

[178] C. Y. Yang, J. C. Tsai, Y. C. Huang, and C. C. Lin, "Effects of a home-based walking program on perceived symptom and mood status in postoperative breast cancer women receiving adjuvant chemotherapy," Journal of Advanced Nursing, vol. 67, no. 1, pp. 158-168, 2011.

[179] L. A. Faul, H. S. Jim, S. Minton, M. Fishman, T. Tanvetyanon, and P. B. Jacobsen, "Relationship of exercise to quality of life in cancer patients beginning chemotherapy," Journal of Pain and Symptom Management, vol. 41, no. 5, pp. 859-869, 2011.

[180] V. Mock, K. H. Dow, C. J. Meares et al., "Effects of exercise on fatigue, physical functioning, and emotional distress during radiation therapy for breast cancer," Oncology Nursing Forum, vol. 24, no. 6, pp. 991-1000, 1997.

[181] S. K. Chambers, B. M. Lynch, J. Aitken, and P. Baade, "Relationship over time between psychological distress and physical activity in colorectal cancer survivors," Journal of Clinical Oncology, vol. 27, no. 10, pp. 1600-1606, 2009.

[182] F. L. Bishop, P. Prescott, Y. K. Chan, J. Saville, E. Von Elm, and G. T. Lewith, "Prevalence of complementary medicine use in 
pediatric cancer: a systematic review," Pediatrics, vol. 125, no. 4, pp. 768-776, 2010.

[183] J. Post-White, M. Fitzgerald, S. Hageness, and S. F. Sencer, "Complementary and alternative medicine use in children with cancer and general and specialty pediatrics," Journal of Pediatric Oncology Nursing, vol. 26, no. 1, pp. 7-15, 2009.

[184] I. Nathanson, E. Sandler, G. Ramírez-Garnica, and S. A. Wiltrout, "Factors influencing complementary and alternative medicine use in a multisite pediatric oncology practice," Journal of Pediatric Hematology/Oncology, vol. 29, no. 10, pp. 705-708, 2007.

[185] D. Tomlinson, T. Hesser, M.-C. Ethier, and L. Sung, "Complementary and alternative medicine use in pediatric cancer reported during palliative phase of disease," Supportive Care in Cancer, vol. 19, no. 11, pp. 1857-1863, 2011.

[186] M. A. Grootenhuis, B. F. Last, J. H. De Graaf-Nijkerk, and M. Van Der Wel, "Use of alternative treatment in pediatric oncology," Cancer Nursing, vol. 21, no. 4, pp. 282-288, 1998.

[187] S. F. Sencer and K. M. Kelly, "Complementary and alternative therapies in pediatric oncology," Pediatric Clinics of North America, vol. 54, no. 6, pp. 1043-1060, 2007.

[188] K. M. Kelly, "Complementary and alternative medical therapies for children with cancer," European Journal of Cancer, vol. 40, no. 14, pp. 2041-2046, 2004.

[189] E. J. Ladas, D. J. Kroll, N. H. Oberlies et al., "A randomized, controlled, double-blind, pilot study of milk thistle for the treatment of hepatotoxicity in childhood Acute Lymphoblastic Leukemia (ALL)," Cancer, vol. 116, no. 2, pp. 506-513, 2010.

[190] S. Phipps, M. Barrera, K. Vannatta, X. Xiong, J. J. Doyle, and M. A. Alderfer, "Complementary therapies for children undergoing stem cell transplantation: report of a multisite trial," Cancer, vol. 116, no. 16, pp. 3924-3933, 2010.

[191] R. Hawks, "Complementary and alternative medicine research initiatives in the Children's Oncology Group and the role of the pediatric oncology nurse," Journal of Pediatric Oncology Nursing, vol. 23, no. 5, pp. 261-264, 2006.

[192] K. M. Kelly, "Bringing evidence to complementary and alternative medicine in children with cancer: focus on nutrition-related therapies," Pediatric Blood and Cancer, vol. 50, no. 2, pp. 490-493, 2008.

[193] J. N. Haun, J. Graham-Pole, and B. Shortley, "Children with cancer and blood diseases experience positive physical and psychological effects from massage therapy," International Journal of Therapeutic Massage \& Bodywork, vol. 2, no. 2, p. 7, 2009.

[194] D. S. Burns, S. L. Robb, and J. E. Haase, "Exploring the feasibility of a therapeutic music video intervention in adolescents and young adults during stem-cell transplantation," Cancer Nursing, vol. 32, no. 5, pp. E8-E16, 2009.

[195] R. J. Barnard, G. K. Grimditch, and J. H. Wilmore, "Physiological characteristics of sprint and endurance Masters runners," Medicine and Science in Sports and Exercise, vol. 11, no. 2, pp. 167-171, 1979.

[196] S. A. Hawkins and R. A. Wiswell, "Rate and mechanism of maximal oxygen consumption decline with aging: implications for exercise training," Sports Medicine, vol. 33, no. 12, pp. 877-888, 2003.

[197] H. K. Kamel, "Sarcopenia and aging," Nutrition Reviews, vol. 61, no. 5, part 1, pp. 157-167, 2003.

[198] D. Y. Chen, T. Y. Hsieh, Y. M. Chen, C. W. Hsieh, J. L. Lan, and F. J. Lin, "Proinflammatory cytokine profiles of patients with elderly-onset rheumatoid arthritis: a comparison with younger-onset disease," Gerontology, vol. 55, no. 3, pp. 250258, 2009.

[199] T. T. Suh and K. W. Lyles, "Osteoporosis considerations in the frail elderly," Current Opinion in Rheumatology, vol. 15, no. 4, pp. 481-486, 2003.

[200] A. Russo, M. Cesari, G. Onder et al., "Depression and physical function: results from the aging and longevity study in the Sirente geographic area (ilSIRENTE study)," Journal of Geriatric Psychiatry and Neurology, vol. 20, no. 3, pp. 131137, 2007.

[201] A. Thalmann, M. Morfeld, and A. Benthien, "Anxiety and depression in the elderly-results of a regional examination," Gesundheitswesen, vol. 74, no. 1, pp. 29-33, 2010.

[202] G. Dal Forno and C. H. Kawas, "Cognitive problems in the elderly," Current Opinion in Neurology, vol. 8, no. 4, pp. 256261, 1995.

[203] S. G. Mohile, Y. Xian, W. Dale et al., "Association of a cancer diagnosis with vulnerability and frailty in older medicare beneficiaries," Journal of the National Cancer Institute, vol. 101, no. 17, pp. 1206-1215, 2009.

[204] F. Baker, S. C. Haffer, and M. Denniston, "Health-related quality of life of cancer and noncancer patients in medicare managed care," Cancer, vol. 97, no. 3, pp. 674-681, 2003.

[205] A. M. Washburn, "Relocation puts elderly nursing home residents at risk of stress, although the stress is short lived: commentary," Evidence-Based Mental Health, vol. 8, no. 2, p. 49, 2005.

[206] L. N. Grinstead, S. Leder, S. Jensen, and L. Bond, "Review of research on the health of caregiving grandparents," Journal of Advanced Nursing, vol. 44, no. 3, pp. 318-326, 2003.

[207] M. P. Jendrek, "Grandparents who parent their grandchildren: circumstances and decisions," Gerontologist, vol. 34, no. 2, pp. 206-216, 1994.

[208] M. Minkler and E. Fuller-Thomson, "The health of grandparents raising grandchildren: results of a national study," American Journal of Public Health, vol. 89, no. 9, pp. 13841389, 1999.

[209] P. S. Lee, Y. M. Lee, J. Y. Lim, R. I. Hwang, and E. Y. Park, "The relationship of stress, social support and depression in the elderly," Taehan Kanho Hakhoe chi, vol. 34, no. 3, pp. 477484, 2004.

[210] J. Möller, J. Hallqvist, L. Laflamme et al., "Emotional stress as a trigger of falls leading to hip or pelvic fracture. Results from the ToFa study-a case-crossover study among elderly people in Stockholm, Sweden," BMC Geriatrics, vol. 9, no. 1, p. 7, 2009.

[211] J. B. Unger, C. A. Johnson, and G. Marks, "Functional decline in the elderly: evidence for direct and stress- buffering protective effects of social interactions and physical activity," Annals of Behavioral Medicine, vol. 19, no. 2, pp. 152-160, 1997.

[212] W. J. Chodzko-Zajko, N. David, A. Maria et al., "American college of sports medicine position stand. Exercise and physical activity for older adults," Medicine \& Science in Sports \& Exercise, vol. 41, no. 7, pp. 1510-1530, 2009.

[213] M. E. Nelson, W. J. Rejeski, S. N. Blair et al., "Physical activity and public health in older adults: recommendation from the American College of Sports Medicine and the American Heart Association," Medicine and Science in Sports and Exercise, vol. 39, no. 8, pp. 1435-1445, 2007. 
[214] H. Lavretsky, L. L. Alstein, R. E. Olmstead et al., "Complementary use of tai chi chih augments escitalopram treatment of geriatric depression: a randomized controlled trial," The American Journal of Geriatric Psychiatry, vol. 19, no. 10, pp. 839-850, 2011.

[215] F. Li, P. Harmer, E. McAuley, K. J. Fisher, T. E. Duncan, and S. C. Duncan, "Tai Chi, self-efficacy, and physical function in the elderly," Prevention Science, vol. 2, no. 4, pp. 229-239, 2001.

[216] C. Lan, J. S. Lai, S. Y. Chen, and M. K. Wong, "Tai Chi Chuan to improve muscular strength and endurance in elderly individuals: a pilot study," Archives of Physical Medicine and Rehabilitation, vol. 81, no. 5, pp. 604-607, 2000.

[217] D. P. K. Leung, C. K. Chan, H. W. Tsang, W. W. Tsang, and A. Y. Jones, "Tai chi as an intervention to improve balance and reduce falls in older adults: a systematic and meta-analytical review," Alternative Therapies in Health and Medicine, vol. 17, no. 1, pp. 40-48, 2011.

[218] M. DiBenedetto, K. E. Innes, A. G. Taylor et al., "Effect of a gentle iyengar yoga program on gait in the elderly: an exploratory study," Archives of Physical Medicine and Rehabilitation, vol. 86, no. 9, pp. 1830-1837, 2005.

[219] L. C. Gonçalves, R. G. D. S. Vale, N. J. F. Barata, R. V. Varejão, and E. H. M. Dantas, "Flexibility, functional autonomy and quality of life (QoL) in elderly yoga practitioners," Archives of Gerontology and Geriatrics, vol. 53, no. 2, pp. 158-162, 2011.

[220] M. Shahidi, A. Mojtahed, A. Modabbernia et al., "Laughter yoga versus group exercise program in elderly depressed women: a randomized controlled trial," International Journal of Geriatric Psychiatry, vol. 26, no. 3, pp. 322-327, 2011. 


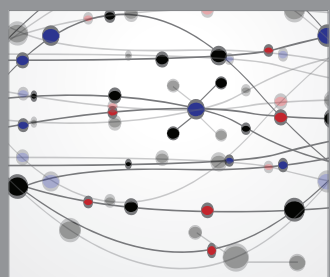

The Scientific World Journal
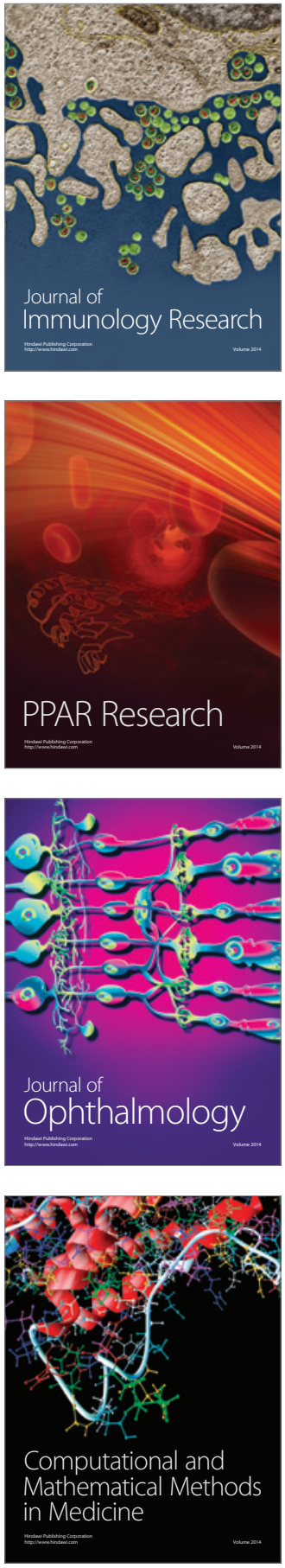

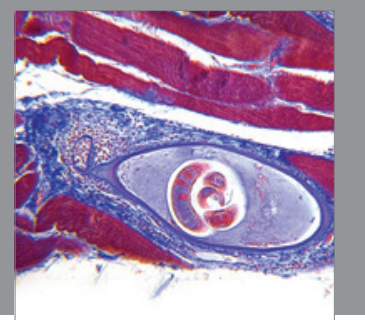

Gastroenterology

Research and Practice
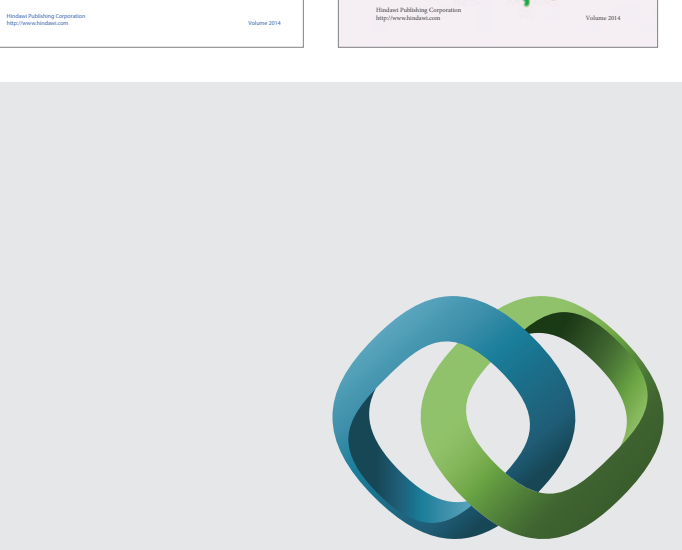

\section{Hindawi}

Submit your manuscripts at

http://www.hindawi.com
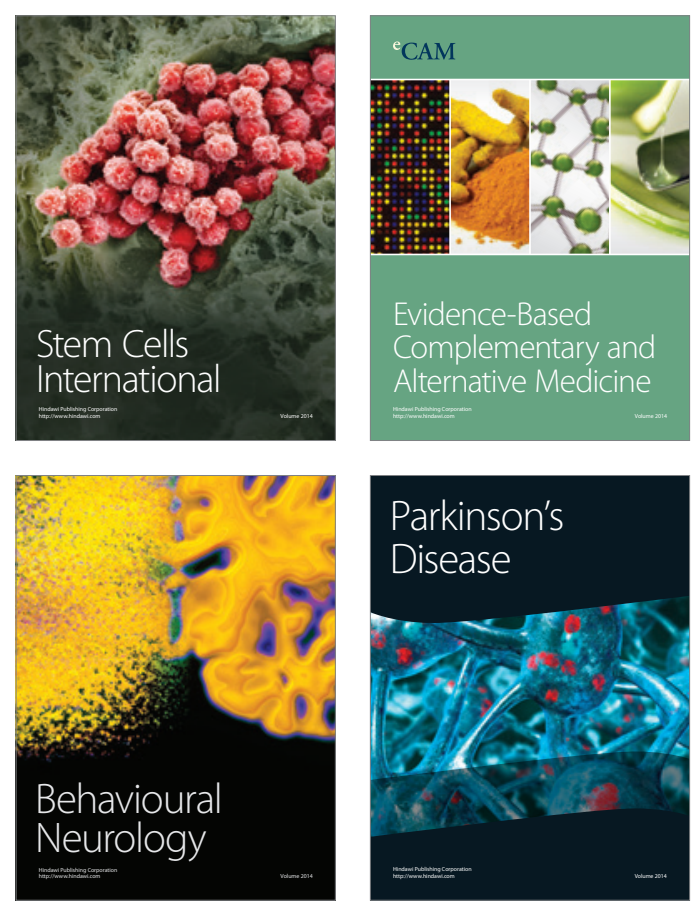

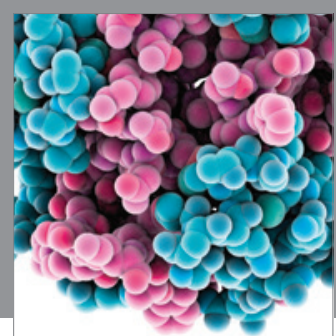

Journal of
Diabetes Research

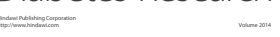

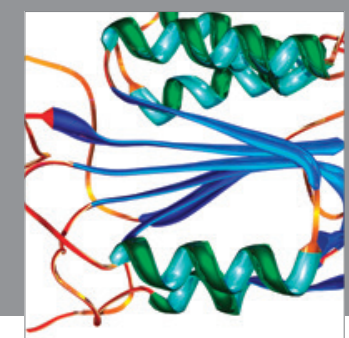

Disease Markers
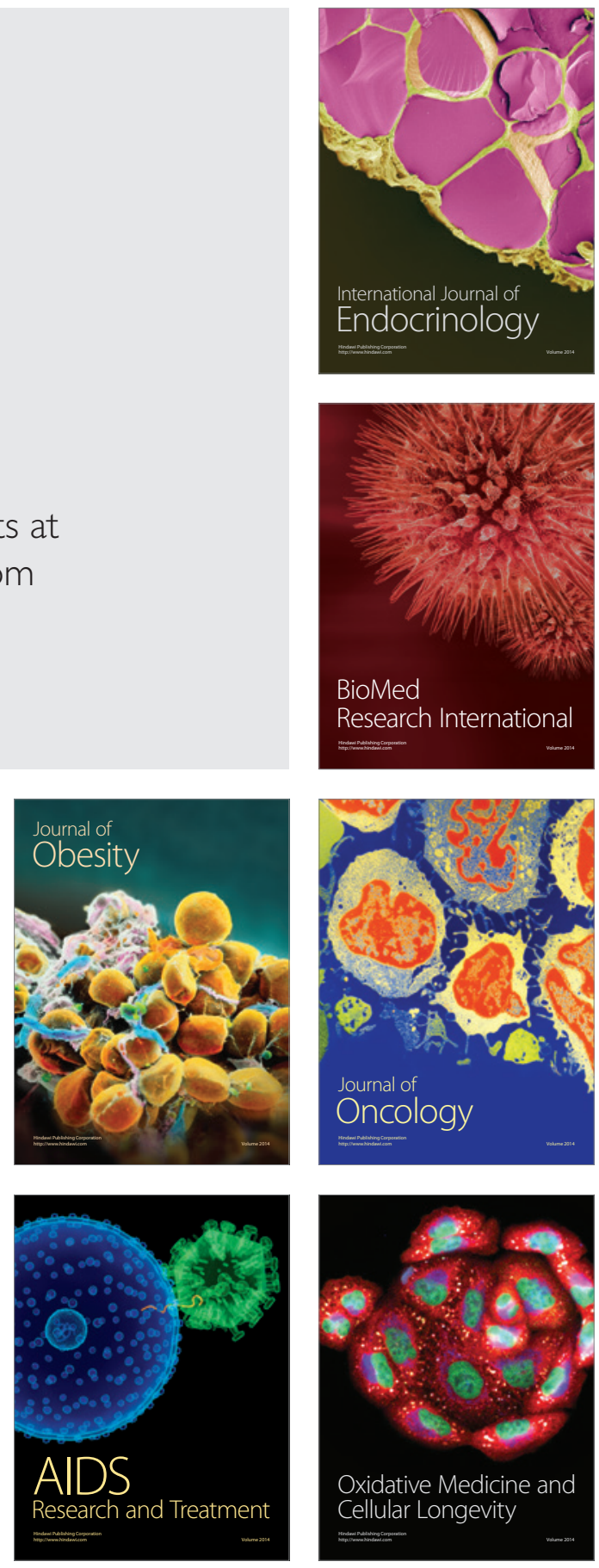